\title{
CARS - Computer Assisted Radiology and Surgery
}

Chair: Michael W. Vannier, MD (USA) 